\title{
Different functional and morphological characteristics in a nonadherent subpopulation of human macrophages recovered by bronchoalveolar lavage
}

\author{
C.M. Sköld*+, C. Barck*, J. Lundahl+, A. Johansson**\#
}

Different functional and morphological characteristics in a nonadherent subpopulation of human macrophages recovered by bronchoalveolar lavage. C.M. Sköld, C. Barck, J. Lundahl, A. Johansson. (C)ERS Journals Ltd 1995.

ABSTRACT: The alveolar macrophages (AMs) constitute a morphologically and functionally heterogenous cell population. The adhesive properties of these cells are important for their role in host defence. To focus on the heterogeneity, a population of nonadherent macrophages were characterized functionally and morphologically. These cells were then compared with the total alveolar macrophage population.

Alveolar cells ( $>95 \%$ alveolar macrophages), were recovered by bronchoalveolar lavage (BAL) from healthy smokers. Nonadherent macrophages were separated by adhesion. The phagocytic capacity and the autofluorescent properties of the cell populations were determined in flow cytofluorometric assays. In addition, electron microscopic evaluation was performed.

The alveolar macrophage adhesion to wells coated with albumin increased in a time-dependent manner. After 15 min, median $47 \%$, interquartile range $42-52 \%$ (uncoated wells $68 \%, 67-72 \%$ ) of the alveolar macrophages were attached; and after $60 \mathrm{~min}, 56 \%, 51-58 \%$ (uncoated wells $73 \%, 71-76 \%$ ) of the alveolar macrophages were attached. The nonadherent alveolar macrophage population had less phagocytic capacity. The cell autofluorescence increased with increasing cell size and cell complexity/granularity in both populations. The nonadherent cells were more autofluorescent, indicating an increased granularity/complexity. These findings were confirmed with electron microscopy. Thus, the nonadherent alveolar macrophages had more cytoplasmic inclusions than the total alveolar macrophage population (volume density median 0.39 , interquartile range $0.35-0.46$ and $0.31,0.26-0.34$, respectively), but less surface protusions.

We conclude that in lavage fluid from human smokers there is an ultrastructurally specific subpopulation of alveolar macrophages, showing less adhesive properties and impaired phagocytic capacity in vitro. These macrophages may be older alveolar cells or, alternatively, airway macrophages. Since only alveolar macrophages from smokers were investigated, we cannot draw any conclusions regarding alveolar cells from nonsmokers. Nevertheless, the heterogeneity of the lavaged cells should be taken into consideration when the functional ability of the alveolar macrophages are evaluated.

Eur Respir J., 1995, 8, 1719-1724.
*Institution of Medicine, Lung Section, and +Dept of Clinical Immunology, Karolinska Hospital, Stockholm, Sweden. **Division of Inhalation Toxicology, Institute of Environmental Medicine, Karolinska Institute, Stockholm, Sweden. \#Dept of Ultrastructure Research, The Wenner-Gren Institute, University of Stockholm, Stockholm, Sweden.

Correspondence: C.M. Sköld

Dept of Thoracic Medicine

Karolinska Hospital

S-171 76 Stockholm

Sweden

Keywords: Adhesion alveolar macrophages bronchoalveolar lavage electron microscopy phagocytosis smoking

\section{Received: July 41994}

Accepted after revision July 101995

The study was supported by grants from the Swedish Heart-Lung Foundation, the Swedish Work Environment Fund and the Swedish Medical Research Council.
Alveolar macrophages (AMs) belong to the mononuclear phagocytic system. They are the main phagocytes in the lung, and act as the principal first cellular defence against inhaled microorganisms and other particles [1-3]. Alveolar macrophages are located in the epithelial lining fluid and are, therefore, the only phagocytes that are directly exposed to the environment.

The bronchoalveolar lavage (BAL) technique in humans has remarkably increased our knowledge of cells and soluble components from the lower respiratory tract [4]. Macrophages recruited by this technique originate, however, not only from the alveolar space, but also from the conducting airways distal to the wedged bronchoscope. Thus, the macrophage populations recovered arise from various sites in the lung and probably have somewhat different functions in vivo.

The BAL cell yield from human smokers compared to nonsmokers is increased four- or fivefold, primarily depending on an increased number of AMs [5]. In addition, the AMs of smokers are generally larger and contain more cytoplasmic inclusions [6-8], and they appear to constitute a morphologically and functionally heterogenous cell population.

The adhesive properties of the mononuclear phagocytes are crucial for their migration and interaction with other cells and extracellular matrix components at the inflammatory site. In the present study, we separated a nonadherent subpopulation of human smokers' macrophages 
by means of an adhesion assay. These cells were, functionally and morphologically, compared with the original (total) alveolar macrophage population. Increased knowledge about the heterogeneity among the recruited BAL cells should improve our understanding of the functional role of macrophages in various disease conditions.

\section{Material and methods}

\section{Subjects}

Healthy smokers (aged 22-43 yrs) participated in the study. Their cigarette consumption was $11.7 \pm 4.0$ packyrs (mean $\pm \mathrm{SD})$, and their present consumption exceeded 10 cigarettes day $^{-1}$ for the last 5 yrs. All subjects had a normal chest radiograph and were free of medication. A routine physical examination showed nothing abnormal. The study had the approval of the local Ethics Committee and informed consent was obtained.

\section{Bronchoalveolar lavage}

BAL was performed by wedging the fibrebronchoscope (Olympus BF, type 4B2, Olympus Optical Co. Ltd, Japan), in a middle lobe bronchus. Five aliquots of saline, $50 \mathrm{~mL}$ each, were then instilled and gently aspirated, and collected in a siliconized bottle kept on ice, which immediately was transported to the laboratory.

\section{Preparation of BAL cells}

The BAL fluid was strained through a double layer of Dacron nets (Millipore, Cork, Ireland). Cells were pelleted by centrifugation at $400 \times \mathrm{g}$ at $4^{\circ} \mathrm{C}$ for $10 \mathrm{~min}$, and the supernatants were poured off. The total number of cells was counted in a Bürker chamber and the viability was tested by trypan blue exclusion. Smears for differential counts were prepared by cytocentrifugation at $500 \mathrm{rpm}$ for $3 \mathrm{~min}$ (Cytospin 2 Shandon, Southern Products Ltd, Runcorn, UK). Smears were stained with MayGrünwald Giemsa and 500 cells were counted. Alveolar cells were finally suspended in RPMI 1640 medium (Seralab Ltd, Crawley Down, Sussex, UK) supplemented with hydroxyethylpiperaxine ethanesulphonic acid (HEPES) ( $5 \mathrm{~mL}$ to $500 \mathrm{~mL}$ of RPMI) to a cell concentration of $1 \times 10^{6}$ cells $\cdot \mathrm{mL}^{-1}$.

\section{Adhesion assay}

Culture wells, with a growth area of $3.83 \mathrm{~cm}^{2}$ (art. no. 25815-12, Corning Laboratory Science Co., New York, NY, USA), were coated by incubating them with human albumin, $10 \mathrm{mg} \cdot \mathrm{mL}^{-1}$ (KABI Vitrum, Stockholm, Sweden), diluted in RPMI 1640 for 30 min under culture conditions (at $37^{\circ} \mathrm{C}$ in an atmosphere of $5 \% \mathrm{CO}_{2}$ and $95 \%$ air). The coating suspension was removed, the wells gently rinsed with phosphate buffered saline
(PBS)-ethylenediamine tetra-acetic acid (EDTA) and airdried. Wells incubated with RPMI 1640 only, were used as controls. The coated wells were then incubated with $500 \mu \mathrm{L}\left(0.5 \times 10^{6}\right.$ cells $)$ of the original cell suspension under culture conditions for 5, 15 and $60 \mathrm{~min}$. The nonadherent cells were removed by gently rinsing with 500 $\mu \mathrm{L}$ RPMI at $37^{\circ} \mathrm{C}$ and were used in the measurements of phagocytosis and autofluorescence (see below). The corresponding original (total) cell population were also incubated at $37^{\circ} \mathrm{C}$ to compensate for the heating in the adhesion assay. The viability (-by trypan blue exclusion) of the nonadherent and the total cell populations were similar (data not shown).

To calculate the adhesion, the absolute number of AMs in the different cell suspensions was counted in a flow cytofluorometer (Epics profile, Coulter Electronics, Hialeah, FL, USA). The percentage of adherent AMs was calculated as follows:

$$
\% \text { adhesion }=[(\text { total }- \text { nonadherent }) / \text { total }] \times 100
$$

where "total" is the cell count in the original cell suspension $\left(0.5 \times 10^{6}\right.$ cells in $500 \mu \mathrm{L}$ RPMI 1640$)$; and "nonadherent" is the cell count in the harvested nonadherent cell population.

The adhesion assay described above was also tested on AMs from nonsmokers; however, no difference was found between AMs from smokers or nonsmokers in initial experiments (data not shown).

\section{Phagocytic assay}

A phagocytic assay, which utilizes fluorescence quenching to differentiate between attached and ingested particles $[9,10]$, and adapted to flow cytofluorometry [11] was used to study C3b-mediated phagocytosis. Serumopsonized, heat-killed, fluorescein isothiocyanate (FITC)conjugated yeast particles (Saccharomyces cerevisiae) (yeast-C3b) were prepared as described previously [11].

In the assay, the nonadherent AM population was compared with the total AM population (controls). These controls consisted of a "Control $4{ }^{\circ} \mathrm{C}$ ", in which the AMs (total population) were incubated in $4^{\circ} \mathrm{C}$ for the same period allowed for adhesion. An additional control sample was incubated, in a polystyrene tube (Sarstedt, Nümbrecht, Germany), at $37^{\circ} \mathrm{C}$ for $60 \mathrm{~min}$ ("Control $37^{\circ} \mathrm{C} "$ ). This was done in order to compensate for the corresponding heating of the nonadherent cells during the adhesion assay.

The phagocytic assay was carried out as follows: nonadherent AMs $\left(0.3-0.4 \times 10^{6}\right.$ cells in $100 \mu \mathrm{L}$ PBSEDTA), removed from the albumin-coated wells at 15 and $60 \mathrm{~min}$, respectively, and total $\mathrm{AM}$ population at the same concentration ("Control $4^{\circ} \mathrm{C} "$ and "Control $37^{\circ} \mathrm{C}$ ") were resuspended in $200 \mu \mathrm{L}$ of Gey's buffer supplemented with $\mathrm{CaCl}_{2}(1.23 \mathrm{mM})$ and $\mathrm{MgCl}_{2} 6 \mathrm{H}_{2} \mathrm{O}(0.51 \mathrm{mM})$ containing $5 \times 10^{6}$ yeast- $\mathrm{C} 3 \mathrm{~b}$ particles per $\mathrm{mL}$. The cell suspensions were incubated at $37^{\circ} \mathrm{C}$ for $15 \mathrm{~min}$, and the phagocytic process was interrupted by adding $1 \mathrm{~mL}$ of cold PBS-EDTA. The fluorescence of attached particles 
was quenched by adding $200 \mathrm{\mu L}$ of trypan blue $\left(2 \mathrm{mg} \cdot \mathrm{mL}^{-}\right.$ 1) at $\mathrm{pH} 6.0$ for $5 \mathrm{~min}$, and then adding $1 \mathrm{~mL}$ of cold PBS-EDTA. The cell samples, treated and not trea-ted with trypan blue were then examined in the flow cytofluorometer. The instrument gave both the percentage and actual number of fluorescent cells within the analysed field. In order to quantify how efficiently an AM can ingest an attached particle, the percentage of AMs with ingested particles compared to the total AM population with attached and/or ingested particles was determined. This was calculated by dividing the percentage of fluorescent AMs after addition of trypan blue by the percentage of cells before addition of the dye and was designated "ingestion". AMs interacting with fluorescent particles, attached and/or ingested, were expressed as "total interaction".

\section{Measurement of cell autofluoroscence}

In order to characterize the nonadherent AMs (albumin coated wells, $15 \mathrm{~min}$ ) with respect to autofluorescent properties, the following experiment was performed. In the flow cytofluorometer, each cell is assigned two values dependent on the light scatter properties as the cell passes a laser beam; forward scatter (FS), reflecting cell size, and side scatter (SS), which yields information of surface topography and internal structures of cells. Based on these two values, each cell is represented by a point in a rectangular co-ordinate system (cytogram). In the present study, the AM cell cluster was divided into three areas with increasing cell size (FS) and cell complexity (SS) (fig. 1). The mean fluorescence intensity of the nonadherent and the total AM population were then determined in each area.

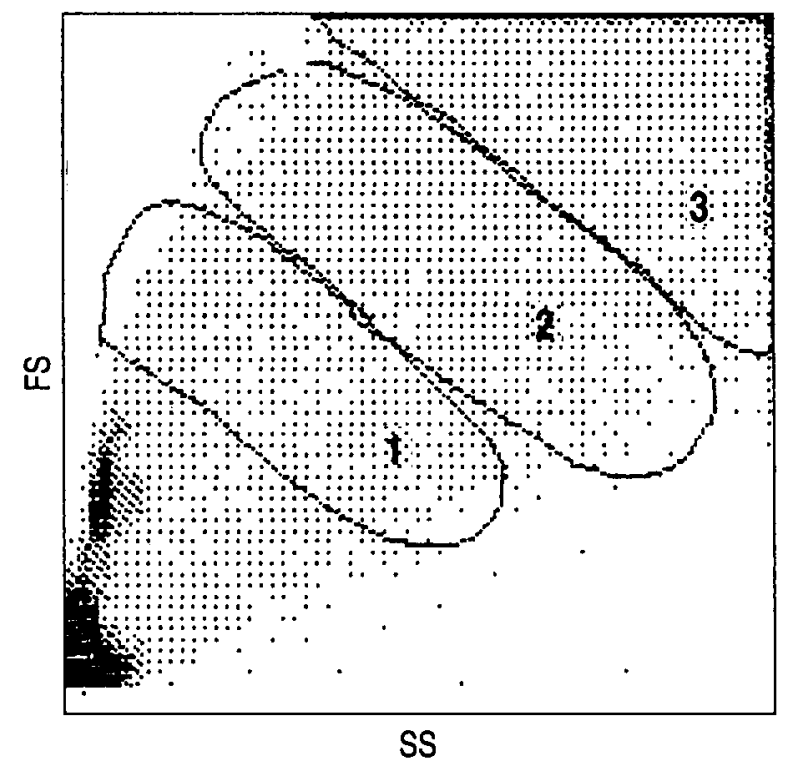

Fig. 1. - Cytogram of the total alveolar macrophage (AM) population from one representative experiment. Each cell is, in principle, represented by a point in a co-ordinate system. Forward scatter (FS) reflecting cell size, and side scatter (SS) reflecting cell complexity/granularity are represented on the $\mathrm{y}$-axis and $\mathrm{x}$-axis, respectively. The AM population are divided into three areas (1,2 and 3), with increasing cell size and complexity.

\section{Electron microscopic evaluation}

Nonadherent cells were removed from the wells as described above. They were pooled to $2-3 \times 10^{6} \mathrm{AMs}$ and fixed in $2 \mathrm{~mL} 2.5 \%$ glutaraldehyde in $0.1 \mathrm{M}$ cacodylate buffer, $\mathrm{pH}$ 7.2. Cell suspensions were then incubated for $30 \mathrm{~min}$ at room temperature, and stored at $4{ }^{\circ} \mathrm{C}$. The total AM population was fixed in the same way. Electron microscopy was also performed on adherent AMs. These cells were exposed to $500 \mu \mathrm{L}$ per well of the same fixative, and incubated for $30 \mathrm{~min}$ at room temperature. The fixed adherent AMs were then removed by gently rubbing with a plastic scraper over the bottom of the well. They were then pooled and stored at $4^{\circ} \mathrm{C}$ until analysed.

The AMs were, thereafter, postfixed in $1 \% \mathrm{OsO}_{4}$ in $0.1 \mathrm{M}$ cacodylate buffer, dehydrated in graded ethanol, and embedded in Agar 100 resin (Agar Scientific Ltd, Stansted, Essex, UK). Thin sections were examined in a Jeol $100 \mathrm{~S}$ electron microscope (Jeol Ltd, Tokyo, Japan). The volume density of intracellular inclusions were estimated from 15-20 selected AM profiles cut through their nuclear regions. To avoid biased selection, the AM profiles nearest to the centre of consecutive gridholes were chosen. The orientation of the AMs were randomized as they were embedded in suspension. Micrographs were taken at a primary magnification of $\times 3,000$. They were enlarged three times and a square lattice, containing 400 intersections, was placed over the pictures. Intersections over inclusions (Ii) were compared with intersections over the cytoplasm (Ic). Intersections over the nuclear profiles were excluded. The ratio $\mathrm{Ii} /(\mathrm{Ic}+\mathrm{Ii})$ was calculated for each AM population. To estimate the surface activity, the number of villous extrusions were counted. AMs with less than 10 surface extrusion profiles were designated smooth. AM population from two subjects were stained for acid phosphatase according to BARKA and ANDERSON [12].

\section{Statistical analysis}

The data are presented as medians with interquartile ranges (IQR). Analysis of significance levels were made with the nonparametric Mann-Whitney U-test.

\section{Results}

\section{General lavage data}

The median recovery of the instilled fluid was $67 \%$ (IQR $62-71 \%$ ). Total cell yield was $49.3 \times 10^{6}$ (IQR $\left.42.4-72.0 \times 10^{6}\right)$, and cell concentration was $338 \times 10^{6}$ cells $\cdot L^{-1}\left(\right.$ IQR $263-453 \times 10^{6}$ cells $\left.\cdot L^{-1}\right)$. The viability was 90\% (IQR 89-91\%). The differential cell count was as follows: alveolar macrophages 96.8\% (IQR 96.0-98.4\%); lymphocytes $1.5 \%$ (IQR 1-2\%); neutrophil granulocytes $0.7 \%$ (IQR $0.4-1.4 \%$ ); and eosinophil granulocytes $0 \%$ (IQR $0-0.2 \%$ ). 


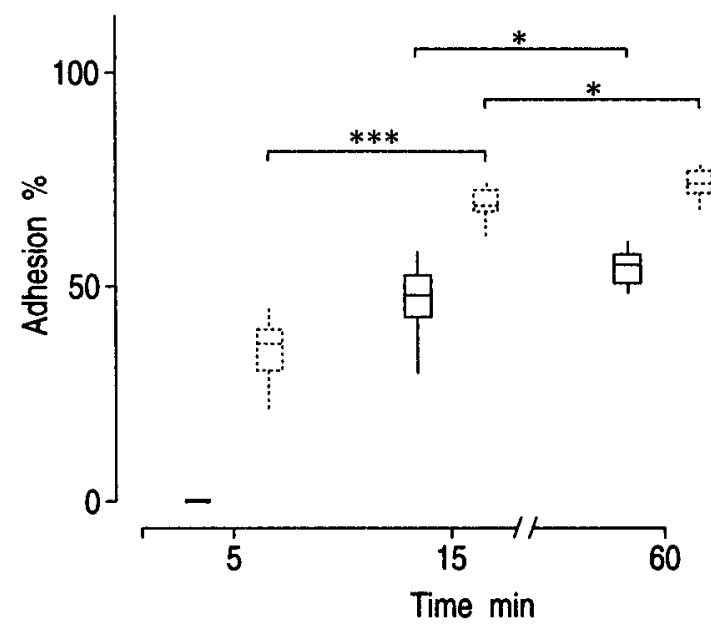

Fig. 2. - Percentage of adhered alveolar macrophages (AMs) at 5, 15 and $60 \mathrm{~min}$. The solid line represents cells from albumin-coated wells $(n=11)$ and the dotted line $(n=9)$ controls (RPMI 1640). The boxes cover values within the interquartile ranges, the central line is at the medium and the minimum and maximum values are also given. $*$ : $\mathrm{p}<0.05 ; * * *: \mathrm{p}<0.001$.

\section{Alveolar macrophage adhesion}

The AM adhesion increased in a time-dependent manner (fig. 2). AMs adhered most strongly to uncoated (RPMI) wells. After $5 \mathrm{~min}$, the percentage of AMs attached to the surface was 36\% (IQR 30-39\%), which increased to $68 \%$ (IQR $67-72 \%)(\mathrm{p}<0.001)$ at $15 \mathrm{~min}$, and to $73 \%$ (IQR 71-76) ( $\mathrm{p}<0.05$ vs $15 \mathrm{~min})$, at $60 \mathrm{~min}$. The AMs adhered somewhat more weakly to the albumin-coated wells: at 5 min no AMs were attached to this surface. At 15 min median 47\% (IQR 42-52\%), and at $60 \mathrm{~min} 56 \%$ (IQR 51-58\%) ( $\mathrm{p}<0.05$ vs $15 \mathrm{~min})$ of the AMs were adhered. Incubation of the cells for $120 \mathrm{~min}$ did not significantly increase the percentage of adhered cells (data not shown).

\section{Phagocytosis}

The total interaction of the AMs with the yeast particles was significantly lower $(p<0.05)$ in the nonadherent AMs compared to the total AM population (table 1). The ingestion of attached yeast particles was also lower in the nonadherent cell population, but the difference was not statistically significant.

Table 1. - Phagocytic function of the total alveolar macrophage (AM) population (control) compared to a subpopulation of nonadherent AMs recovered after 15 and $60 \mathrm{~min}$ adherence to culture wells

\begin{tabular}{|c|c|c|}
\hline & $\begin{array}{c}\text { Total interaction } \\
\%\end{array}$ & $\begin{array}{c}\text { Ingestion } \\
\%\end{array}$ \\
\hline Control $37^{\circ} \mathrm{C}$ & $102(86-106)$ & $87(83-90)$ \\
\hline \multirow{2}{*}{ Nonadherent AMs } & $81(68-89)^{*}$ & $80(71-93)$ \\
\hline & $77(64-92)^{*}$ & $79(73-89)$ \\
\hline
\end{tabular}

All phagocytosis experiments were carried out at $37^{\circ} \mathrm{C}$. The assay is described in detail in the text. Values are percentage of control $\left(4^{\circ} \mathrm{C}\right)$ and are presented as median with interquartile range in parenthesis $(\mathrm{n}=8)$. $*: \mathrm{p}<0.05$ vs control $\left(37^{\circ} \mathrm{C}\right)$.
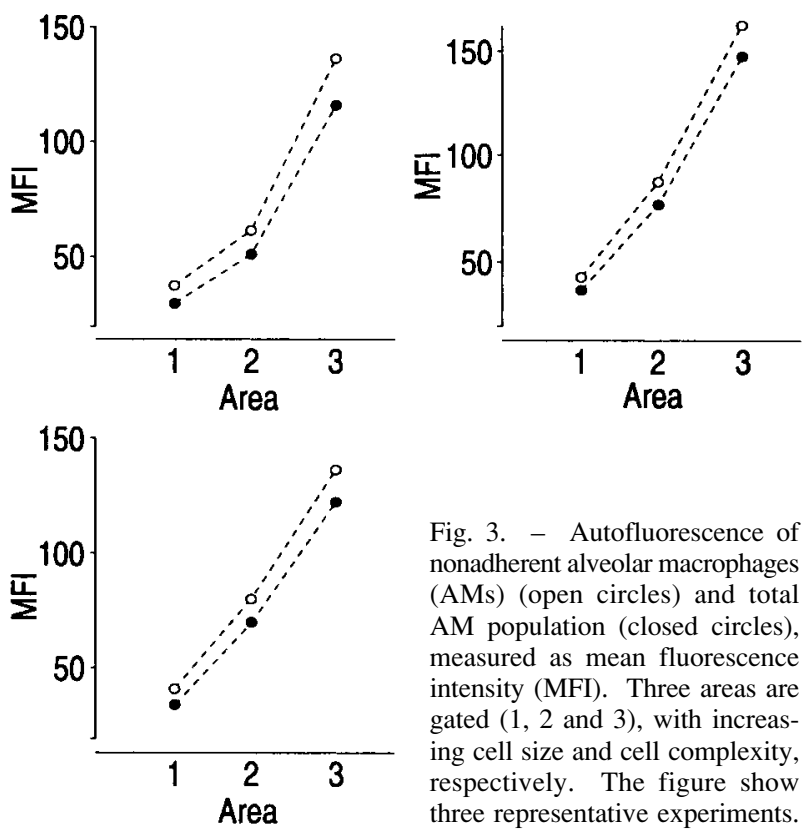

Fig. 3. - Autofluorescence of nonadherent alveolar macrophages (AMs) (open circles) and total AM population (closed circles), measured as mean fluorescence intensity (MFI). Three areas are gated $(1,2$ and 3$)$, with increasing cell size and cell complexity, respectively. The figure show three representative experiments.

\section{Autofluorescence}

The fluorescence of the AMs increased with increasing cell size and complexity (fig. 3). Thus, the highest fluorescence was found in the largest and most complex/granular cells. The nonadherent AMs had higher fluorescence intensity (in all areas) than the original (total) population.

a)

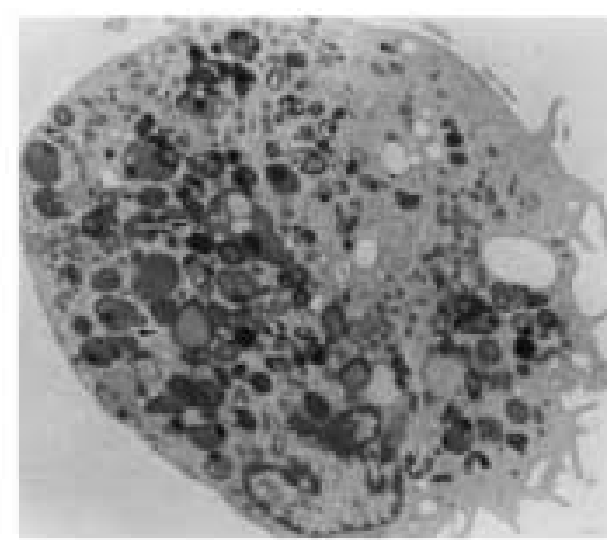

b)

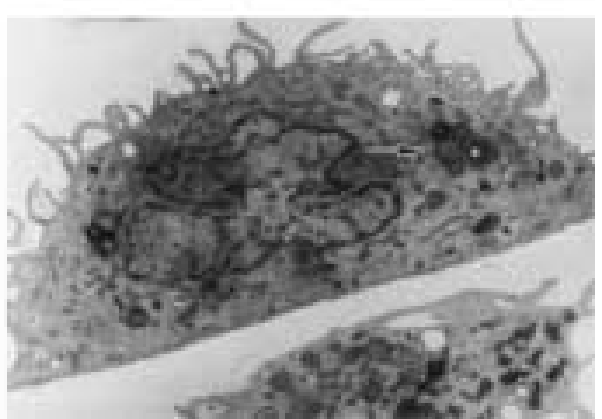

Fig. 4. - Electronmicrograph $(\times 7,000$ magnification $)$ of a nonadherent (a) and an adherent (b) alveolar macrophage (AM). Several cytoplasmic inclusions (arrows) are observed, above all in the nonadherent AM. The adherent AM appears to have more surface activity. 
Table 2. - Electron microscopic (EM) characteristics of nonadherent and total alveolar macrophage (AM) population

\begin{tabular}{lcc}
\hline EM finding & Nonadherent AM & $\begin{array}{c}\text { Total AM } \\
\text { population }\end{array}$ \\
\hline $\begin{array}{c}\text { Volume density of } \\
\text { cytoplasmic inclusions }\end{array}$ & $\begin{array}{c}0.39 * \\
(0.35-0.46) \\
73 * *\end{array}$ & $\begin{array}{c}0.31 \\
\text { Smooth cells } \\
\% \text { of all cells }\end{array}$ \\
\hline
\end{tabular}

Values are presented as median and interquartile range in parenthesis $(\mathrm{n}=7)$. *: $\mathrm{p}<0.05 ; * * \mathrm{p}<0.01$ vs total AM population.

\section{Electron microscopic findings}

AMs from both populations contained several complex inclusions, size ranging $0.1-20 \mu \mathrm{m}$, probably consisting of undigested material from the tobacco smoke (fig. 4). In the inclusions, dense areas were intermingled with more electronlucent parts. Many inclusions contained lipid-like zones and vacuoles; positive staining for acid phosphatase suggested a lysosomal connection. Nonadherent AMs, from every single subject, contained more cytoplasmic inclusions than the total cell population. This difference, measured as the volume density of inclusions, was statistically significant $(\mathrm{p}<0.05)$ (table 2$)$. There were also significantly $(\mathrm{p}<0.001)$ more smooth cells among the nonadherent cells than in the total population (table 2).

\section{Discussion}

AMs from human smokers ultrastructurally differ from those of nonsmokers; they are larger [8, 13], contain more cell organelles, pseudopodia [8, 14] and several inclusions ("smokers inclusions") $[6,7,15,16]$. The heterogeneity seems to be more pronounced in AMs of smokers than nonsmokers, as indicated by differences in their light scattering and autofluorescent properties [17, 18].

We conducted this study with AMs from smokers, as pilot experiments in our laboratory had showed no differences in in vitro adhesion properties between AMs from human smokers and nonsmokers. This is in agreement with previous studies by others $[19,20]$. On the other hand, RASP et al. [21] found that AMs from smokers had an impaired adherence to nylon fibres. These contradictory results could, in part, be explained by different methods. In addition, the lower adherence in the AMs from smokers in the study by RASP et al. [21] was not detected in AMs from subjects who had abstained from smoking for some weeks. This indicates that their findings was not due to the presence of smoke components in the AMs, but more an "acute" effect of the tobacco smoke per se.

By the use of an adhesion assay we could separate a nonadherent AM population. This subpopulation of macrophages was compared with the original (total) AMs. The nonadherent cells had, by electron microscopy, significantly more inclusion bodies and less surface protusions.
Furthermore, the nonadherent AMs, in all areas measured, had a higher fluorescence intensity than the corresponding total population. This fluorescence is due to endocytosed fluorescent components from tobacco smoke, and increased fluorescence is associated with increased complexity/granularity of the cells [17, 22, 23].

The majority of AMs are transported by ciliary movements upwards, becoming airway macrophages [24]. These airway macrophages are functionally less active than their precursors, the AMs [25]. By performing isolated bronchial lavages, RANKIN et al. [26] described a population of airway macrophages and compared them with AMs. By electron microscopy, they found characteristics similar to our present findings in the nonadherent cell population. Moreover, LAPLANTE and LEMAIRE [27] found, by performing fractionated BAL in rats, that AMs from the first recovered portion had less adhesive properties. These previous studies together with the present results, makes it reasonable to believe that the nonadherent cells in the present study represents airway macrophages or older AMs that are cleared from the alveolar space by the mucociliary transport mechanism.

In the present study, the phagocytic capacity was impaired in the nonadherent cell population compared to the total AMs. The total interaction differed statistically whilst the ingestion did not, although the value was lower. Since interaction with the prey is a prerequisite for ingestion, we believe that the total interaction is the more sensible parameter in the phagocytic process. One reason why the ingestion did not differ statistically could be the fact that the total AM sample contained both adherent and nonadherent cells. Many in vitro phagocytic assays include only adherent phagocytes. We believe that in such assays there might be a selection of cells, and that nonadherent, less phagocytic cells can be excluded. This should be taken into consideration when results from such studies are interpreted.

Some earlier reports have focused on the heterogeneity of human AMs [28-32]. Other investigators [33, 34] have concluded, by means of monoclonal antibodies, that their nonadherent AM subset consisted predominantly of antigen-presenting dendritic cells with a very low phagocytic activity, and that the phagocytic cell population were equivalent to the adherent subpopulation. Our present study cannot confirm whether the nonadherent macrophages are more or less antigenpresenting. However, our electron microscopic findings clearly indicate the presence of ingested material from tobacco smoke, emphasizing the phagocytic capacity of these cells.

In conclusion, in human smokers an ultrastructurally specific subpopulation of macrophages can be identified showing less in vitro adhesive properties and an impaired phagocytic capacity. These loosely adherent cells could be older AMs or, alternatively, airway macrophages. Since, in the present study, only smokers were lavaged, we cannot draw any conclusions regarding a nonadherent subpopulation of macrophages from nonsmokers. Nevertheless, when evaluating AMs recruited by BAL, it seems important to take their heterogeneity into consideration. 
Acknowledgements: The authors acknowledge M. Hallgren for expert technical assistance.

\section{References}

1. du Bois RM. The alveolar macrophage. Thorax 1985; 40: 321-327.

2. Coonrod JD. Role of leukocytes in lung defense. Respiration 1989; 55 (Suppl. 1): 9-13.

3. Reynolds HY. Host defense impairments that may lead to respiratory tract infections. Clin Chest Med 1988; 8: 189-208.

4. Reynolds HY. Bronchoalveolar lavage. Am Rev Respir Dis 1987; 135: 250-263.

5. Cherniack RM (co-ordinator). Bronchoalveolar lavage constituents in healthy individuals, idiopathic pulmonary fibrosis, and selected comparison groups. Am Rev Respir Dis 1990; 141: S169-S202.

6. Pratt SA, Finley TN, Smith MH, Ladman AJ. A comparison of alveolar macrophages and pulmonary surfactant (?) obtained from the lungs of human smokers and nonsmokers by endobronchial lavage. Anat Rec 1969; 163: 497-508.

7. Pratt SA, Smith SA, Ladman AJ, Finley TN. The ultrastructure of alveolar macrophages from human cigarette smokers and nonsmokers. Lab Invest 1971; 24: 331-338.

8. Harris JO, Swenson JE, Johnson III JE. Human alveolar macrophages: comparison of phagocytic ability, glucose utilization, and ultrastructure in smokers and nonsmokers. J Clin Invest 1970; 49: 2086-2096.

9. Hed J. The extinction of fluorescence by crystal violet and its use to differentiate between attached and ingested microorganisms in phagocytosis. FEMS Microbiol Lett 1977; 1: 357-361.

10. Sahlin S, Hed J, Rundquist I. Differentiation between attached and ingested immune complexes by a fluorescence quenching cytofluorometric assay. J Immunol Methods 1983; 60: 115-124.

11. Hed J, Halldén G, Johansson SGO, Larsson P. The use of fluorescence quenching in flow cytofluorometry to measure the attachment and ingestion phases in phagocytosis in peripheral blood without prior cell separation. J Immunol Methods 1987; 101: 119-125.

12. Barka T, Anderson PJ. Histochemical methods for acid phosphatase using hexazonium pararosanilin as coupler. J Histochem Cytochem 1962; 10: 741-753.

13. Sibille Y, Reynolds HY. Macrophages and polymorphonuclear neutrophils in lung defense and injury. $A m$ Rev Respir Dis 1990; 141: 471-501.

14. Plowman PN. The pulmonary macrophage population of human smokers. Ann Occup Hyg 1982; 25: 393-405.

15. Brody AR, Craighead JE. Cytoplasmic inclusions in pulmonary macrophages of cigarette smokers. Lab Invest 1975; 32: 125-132.

16. Choux R, Pautrat G, Viallat J, Farisse P, Boutin C. Inorganic cytoplasmic inclusions in alveolar macrophages: the role of cigarette smoking. Arch Pathol Lab Med 1978; 102: 79-83.

17. Sköld CM, Eklund A, Halldén G, Hed J. Autofluorescence in human alveolar macrophages from smokers: relationship to cell surface markers and phagocytosis. Exp Lung Res 1989; 15: 823-835.
18. Sköld CM, Eklund A, Halldén G, Hed J. Different cell surface and phagocytic properties in mononuclear phagocytes from blood and alveoli. APMIS 1990; 98: 415422.

19. McGowan SE, Heckman JG. Mechanisms of serumenhanced adhesion of human alveolar macrophages to epithelial cells. Lung 1991; 169: 215-226.

20. Territo MC, Golde DW. The function of human alveolar macrophages. J Reticuloend Soc 1979; 25: 111-120.

21. Rasp FL, Clawson CC, Hoidal JR, Repine JE. Reversible impairment of the adherence of alveolar macrophages from cigarette smokers. Am Rev Respir Dis 1978; 118: 979-986.

22. Sköld CM, Eklund A, Hed J, Hernbrand R. Endocytosis of cigarette-smoke condensate by rabbit alveolar macrophages in vitro measured as fluorescence intensity. Eur Respir J 1992; 5: 53-58.

23. Sköld CM, Anderson K, Hed J, Eklund A. Short-term in vivo exposure to cigarette smoke increases the fluorescence in rat alveolar macrophages. Eur Respir J 1993; 6: 1167-1172.

24. Brain JD. Macrophages in the respiratory tract. In: Fishman AP, Fisher AB, eds. Handbook of Physiology, the Respiratory System. Vol. 1. Bethesda, Am Physiol Soc, 1985; pp. 447-471.

25. Lehnert BE, Valdez YE, Sebring RJ, Lehnert NM, Saunders GC, Steinkamp JA. Airway intraluminal macrophages: evidence of origin and comparisons to alveolar macrophages. Am J Respir Cell Mol Biol 1990; 3: 377-391.

26. Rankin JA, Marcy T, Rochester CL, et al. Human airway macrophages: a technique for their retrieval and a descriptive comparison with alveolar macrophages. Am Rev Respir Dis 1992; 145: 928-933.

27. Laplante C, Lemaire I. Interactions between alveolar macrophage subpopulations modulate their migratory function. Am J Pathol 1990; 136: 199-206.

28. Zwilling BS, Campolito LB, Reiches NA. Alveolar macrophage subpopulations identified by differential centrifugation on a discontinuous albumin density gradient. Am Rev Respir Dis 1982; 125: 448-452.

29. Hance AJ, Douches S, Winchester RJ, Ferrans VJ, Crystal RG. Characterization of mononuclear phagocyte subpopulations in the lung by using monoclonal antibodies: changes in alveolar macrophage phenotype associated with pulmonary sarcoidosis. J Immunol 1985; 134: 284-292.

30. Gant VA, Hamblin AS. Human bronchoalveolar lavage heterogeneity demonstrated by histochemistry, surface markers and phagocytosis. Clin Exp Immunol 1985; 60: 539-545.

31. Sandron D, Reynolds HY, Venet A, Laval A-M, IsraelBiet D, Chretien J. Human alveolar macrophage subpopulations isolated on discontinuous albumin gradients: functional data in normals and sarcoid patients. Eur $J$ Respir Dis 1986; 69: 226-324.

32. Nakstad B, Lyberg T, Skjörten F, Boye NP. Subpopulations of human lung alveolar macrophages: ultrastructural features. Ultrastruct Pathol 1989; 13: 1-13.

33. Poulter LW. Changes in lung macrophages during disease. FEMS Microbiol Immunol 1990; 64: 327-332.

34. Spiteri M, Poulter LW. Characterization of immune inducer and suppressor macrophages from the human lung. Clin Exp Immunol 1991; 83: 157-162. 